Postprint version. Original publication in:

Ecological Entomology (2007) 32:194-200

doi: http://dx.doi.org/10.1111/j.1365-2311.2006.00858.x

\title{
Host plant finding in the specialised leaf beetle Cassida canaliculata: an analysis of small-scale movement behaviour
}

\author{
Annette Heisswolf, Sandra Ulmann, Elisabeth Obermaier, \\ Oliver Mitesser, Hans Joachim Poethke
}

Field Station Fabrikschleichach, University of Würzburg, Glashüttenstrasse 5, D-96181 Rauhenebrach

\begin{abstract}
Host plant finding in walking herbivorous beetles is still poorly understood. Analysis of small-scale movement patterns under semi-natural conditions can be a useful tool to detect behavioural responses towards host plant cues.

In this study, the small-scale movement behaviour of the monophagous leaf beetle Cassida canaliculata Laich. (Coleoptera: Chrysomelidae) was studied in a semi-natural arena $(r=1 \mathrm{~m})$. In three different settings, a host (Salvia pratensis L., Lamiales: Lamiaceae), a non-host (Rumex conglomeratus Murr., Caryophyllales: Polygonaceae), or no plant was presented in the centre of the arena.

The beetles showed no differences in the absolute movement variables, straightness and mean walking speed, between the three settings. However, the relative movement variables, mean distance to the centre and mean angular deviation from walking straight to the centre, were significantly smaller when a host plant was offered. Likewise, the angular deviation from walking straight to the centre tended to decline with decreasing distance from the centre. Finally, significantly more beetles were found on the host than on the non-host at the end of all the trials.

It is concluded that $C$. canaliculata is able to recognise its host plant from a distance. Whether olfactory or visual cues (or a combination of both) are used to find the host plant remains to be elucidated by further studies.
\end{abstract}

Keywords. Arena experiment, Coleoptera, Chrysomelidae, olfaction, Rumex, Salvia pratensis, vision, walking.

\section{INTRODUCTION}

Although the ability of insects to locate host plants from a distance has been studied in many flying and walking species (e.g. Feeny et al., 1970; Visser \& Avé, 1978; Blight et al., 1995; Bartlet et al., 1997; Barata et al., 2000; Kalberer et al., 2001; van Tol \& Visser, 2002; Zhang \& Schlyter, 2004; Bruce et al., 2005; Kalberer et al., 2005), the 
analysis of behavioural responses to host plant cues - and in particular the analysis of movement behaviour - has been largely restricted to flying insects (Willis et al., 1994; Guerrieri, 1996; Baker \& Vickers, 1997; Witzgall, 1997; Vickers, 2000).

Although Jermy et al. (1988) had used a semi-natural arena experiment to analyse the movement behaviour of the Colorado potato beetle, Leptinotarsa decemlineata, in the presence of host plants almost 20 years ago, such studies are still only rarely conducted because of the spatial and personnel requirements. Instead, most experimental studies on host plant recognition use olfactometers, locomotion compensators, or wind tunnels within a laboratory (Böhm, 1995; McIntyre \& Vaughn, 1997; van Loon et al., 2000; Barata \& Araújo, 2001; Tinzaara et al., 2003; Kalberer et al., 2005). However, these experiments often restrict the behavioural repertoire of the animal under study. For example, on top of a locomotion compensator, an insect can choose to walk towards or away from the stimulus and can change its walking pattern and speed, but it cannot change its position in relation to the stimulus. Consequently, several experimental series are needed to analyse whether the insects behave differently depending on the distance to the stimulus. Thus, experimental conditions in which the insect is allowed to move completely freely may be more useful for detecting behavioural differences in response to attractive and non-attractive stimuli.

In this study, a semi-natural arena was used to examine whether the strictly monophagous leaf beetle, Cassida canaliculata Laich. (Coleoptera: Chrysomelidae), is able to recognise its host plant from a distance. Recent laboratory experiments suggested that it needs contact cues to identify its host, Salvia pratensis L. (Lamiales: Lamiaceae), whereas it showed only a very weak reaction to olfactory cues in a six-chamber olfactometer and on a locomotion compensator (Heisswolf et al., 2007). From preliminary studies (D. Gabler, unpublished data) it can be concluded that $C$. canaliculata is able to use visual cues for orientation, but whether such cues are also important for host plant finding remains to be analysed. Thus, host plant recognition from a distance seemed rather unlikely in $C$. canaliculata.

Now, the ability of $C$. canaliculata to recognise its host plant Salvia pratensis was analysed by comparing the beetles' movement pattern depending on whether (1) the host plant meadow sage (S. pratensis), (2) the non-host plant clustered dock (Rumex conglomeratus Murr., Caryophyllales: Polygonaceae), or (3) no plant at all was placed in the centre of the arena. Moreover, it was evaluated whether the beetles were more often found on the host than on the non-host plant during and at the end of the trials. 


\section{MATERIALS AND METHODS}

\section{Species under study}

The specialised tortoise beetle, C. canaliculata Laich. (Coleoptera: Chrysomelidae), is strictly monophagous on meadow sage (S. pratensis L., Lamiales: Lamiaceae) (Wencker \& Silbermann, 1866; Bourgeois \& Scherdlin, 1899; Reitter, 1912; Graser, 1984; Trautner et al., 1989; A. Heisswolf \& D. Gabler, unpublished data), on which all developmental stages are exclusively found. Until now, little has been published on the ecology of $C$. canaliculata (Steinhausen, 1949; Trautner et al., 1989; Heisswolf et al., 2005, 2006).

Adults of $C$. canaliculata were collected in the 'Hohe Wann' nature reserve in Northern Bavaria, Germany (50 03' N, $\left.10^{\circ} 35^{\prime} \mathrm{E}\right)$ in May and June 2005. During the whole period of experimentation, they were kept in boxes $(115 \times 115 \times 61 \mathrm{~mm})$ with a gauze lid (500-mm mesh) at room temperature and LD 16:8 $\mathrm{h}$. The bottom of each box was covered with filter paper, and the beetles were fed on leaves of $S$. pratensis. Before testing, the beetles were starved for $3 \mathrm{~h}$.

The host plant, meadow sage (S. pratensis; Fig. 1a), is very common in southern Germany. It is a perennial herb with a ground rosette that grows on dry meadows and field edges (Schmeil \& Fitschen, 1996). The non-host plant, clustered dock (Rumex conglomeratus Murr., Caryophyllales: Polygonaceae; Fig. 1b), is a very common ruderal plant all over Germany. It is a wintergreen perennial herb, also with a ground rosette, which grows in all kinds of meadows (Düll \& Kutzelnigg, 2005). This plant was chosen, as its growth form resembles that of S. pratensis but - belonging to a completely different plant order - it presumably emits a different blend of volatiles.

\section{Arena experiments}

The experiments were performed in a circular arena $(r=1 \mathrm{~m})$ inside a greenhouse in the garden of the Field Station Fabrikschleichach (University of Würzburg). The bottom of the arena was covered with clay ( $1.5 \mathrm{~cm}$ deep). The edge of the arena (height $30 \mathrm{~cm}$ ) consisted of dark grey plastic, which was treated with Fluon ${ }^{\circledR}$ to prevent the beetles from escaping. There was a hole (diameter $11 \mathrm{~cm}$ ) in the centre of the arena into which a pot could be placed.

The movement behaviour of adult $C$. canaliculata individuals was recorded in three different settings, in which either a potted host plant ('Salvia'), a potted non-host plant ('Rumex'), or a pot filled only with soil ('No Plant') was placed in the middle of the arena. In each setting, 24 beetles were released individually into the arena on a circle with a distance of $50 \mathrm{~cm}$ to the centre of the arena. The release points were chosen randomly in $30^{\circ}$ steps along this circle, and each beetle was tested only once. The 


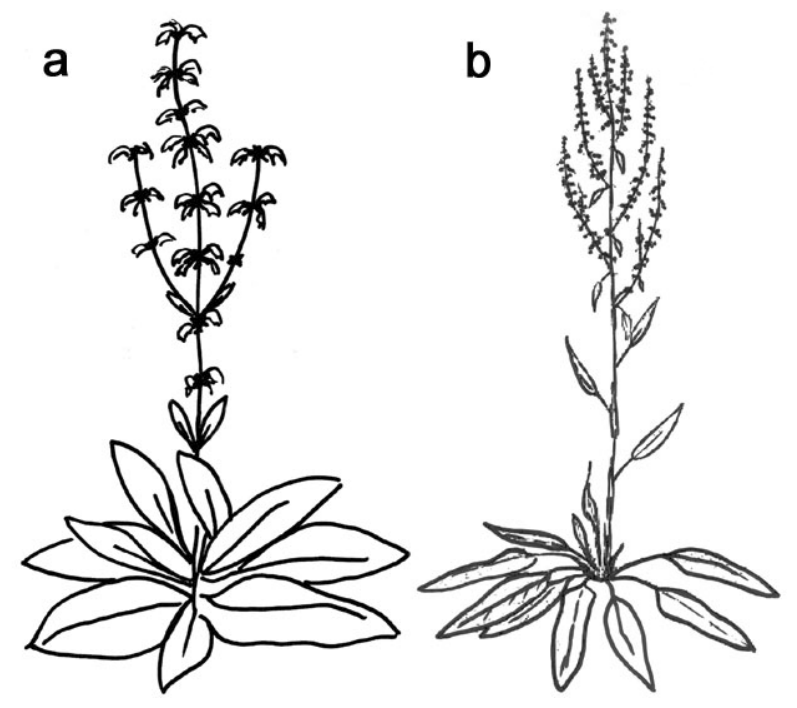

Figure 1: Schematic drawings of (a) the host plant S. pratensis L. (Lamiales: Lamiaceae) and (b) the non-host plant $R$. conglomeratus Murr. (Caryophyllales: Polygonaceae). Drawings by A. Heisswolf.

beetles were released in a supine position, and the observation was started when the beetle had rolled over of its own accord. Then, the location of the beetle was marked for $10 \mathrm{~min}$ in 30-s intervals with consecutively numbered paper discs.

A digital picture (Sony Cyber Shot DSC-F828; $5 \mathrm{Mpx}$ ) was taken of the movement path of each beetle. Before analysis, all pictures were converted from jpg into pgm format and reduced to $1296 \times 972$ pixels with the ImageMagick 6.2.3-Q8 software (www.imagemagick.org). The photographs were analysed with the statistic software $\mathrm{R}$ 2.1.1 (R Development Core Team, 2005) using the 'pixmap' package (Bivand et al., 2004).

The walking behaviour of beetles can be divided into two components: (a) the absolute movement, which describes how fast and how straight the beetles move; (b) the relative move ment, which characterises how the beetles move relative to a cue. Regarding the absolute movement pattern, the following variables were recorded for each beetle: track length $(\mathrm{m})$, i.e. the sum of all step lengths; net distance $(\mathrm{m})$, i.e. the vector length from start to end point; mean walking speed $(\mathrm{cm} / \mathrm{s})$. The straightness of the beetles' path was calculated as the quotient of net distance and track length and can range from 0 to 1 . Then, straightness and mean walking speed were compared between the three treatment groups.

Regarding the beetles' movement relative to the cue (which was always in the centre of the arena), the mean distance to the centre of the arena (m) and the mean angular deviation from walking straight to the centre of the arena $\left(^{\circ}\right)$ were registered. For the calculation of the angular deviation, only the absolute values were used, i.e. $0^{\circ}$ 
denotes walking straight to the centre, $90^{\circ}$ stands for walking across to the centre, and $180^{\circ}$ means walking straight away from the centre.

To analyse whether both absolute and relative walking patterns change with the distance to the centre of the arena, the standardised walking speed, i.e. (walking speed per step - mean walking speed)/mean walking speed, and the angular deviation from walking straight to the centre $\left(^{\circ}\right)$ were also calculated for each step.

\section{Individual-based simulations}

To estimate how many beetles would reach the centre of the arena by chance alone, computer simulations of the movement of the beetles were performed. The virtual arena had the same spatial dimensions as the one used in the greenhouse experiments $(r=1 \mathrm{~m})$, and the beetles were also released randomly on a circle with a radius of 0.5 $\mathrm{m}$ around the centre of the arena. In analogy to the greenhouse experiment, movement was simulated for $10 \mathrm{~min}$ in 20 steps of $30 \mathrm{~s}$ each.

The movement behaviour of the beetles was modelled as a correlated random walk. In discrete time, a correlated random walk is characterised by the distribution of step lengths and turning angles between consecutive movement steps (Kitching, 1971; Kareiva \& Shigesada, 1983; Byers, 2001; Pfenning et al., 2004). On the basis of the observed movement patterns in the greenhouse experiments, turning angles were drawn from the uniform interval $\left[-40^{\circ} \ldots+40^{\circ}\right]$, and step lengths were drawn from the uniform interval $\left[\begin{array}{lll}0 & \ldots & 0.8 \mathrm{~cm}\end{array}\right]$. In the greenhouse experiments, the diameter of the pot was $11 \mathrm{~cm}$. As the plants tended to have a slightly greater diameter, the diameter of the arena centre in our simulations was $20 \mathrm{~cm}$. Simulation experiments should thus slightly overestimate the number of beetles reaching the centre.

Three different scenarios of edge behaviour were implemented in the simulations to analyse the effect of this movement characteristic for the number of beetles expected to reach the centre by chance. The first scenario ('edge') reproduces the beetles' behaviour observed in the greenhouse experiment: after contact with the edge, the beetles adjusted their walking direction parallel to the edge and then moved on according to the movement pattern described above. The second scenario ('reflecting edge') was chosen as it is often implemented in simulation studies with limited spatial dimensions (Grünbaum, 1998; Turchin, 1998; Schmitz, 2000). In this setting, the beetles were reflected from the edge of the arena in the same angle as they met the edge. Finally, the third scenario ('repelling edge') represents the most extreme scenario in which the beetles that hit the edge adjusted their walking direction directly towards the centre of the arena. For each scenario, 100000 simulation runs were performed. 


\section{Statistical analyses}

As we were interested in the movement pattern of freely moving beetles, all data points reflecting constrained movement conditions were removed before analysis. These cases include: (1) all data points in which a beetle was sitting on the plant, as these would artificially reduce the beetle's mean walking speed, its mean distance to the centre, and its mean angle to the centre; (2) all data points in which a beetle had contact with the edge of the arena, as these data would artificially increase the number of steps perpendicular to the centre.

Then, all variables were tested for normal distribution using the Shapiro-Wilk test. The three settings were compared using the Kruskal-Wallis H-test. When this test was significant, Mann-Whitney U-tests were used for pairwise comparisons between the groups. Regarding the null hypothesis that the beetles move completely at random through the arena, the mean distance of all points within the arena to the centre is $2 / 3$ $\mathrm{m}$, and the mean angular deviation from walking straight to the centre is $90^{\circ}$. Thus, the variables 'mean distance from the centre' and 'mean angular deviation from walking straight to the centre' were further compared with these critical values with the Wilcoxon signed rank test. The number of beetles arriving at the host or the non-host, as well as the location of the beetles at the end of the trial (plant, arena, edge) was compared using Fisher's exact test. Relationships between the distance of a beetle from the centre and its standardised walking speed as well as its angular deviation from walking straight to the centre (cosine-transformed) were analysed using Spearman rank correlation. All statistical procedures were calculated with the software package R 2.2.1 (R Development Core Team, 2005).

\section{RESULTS}

\section{Location during and at the end of each trial}

During the trials, significantly more beetles visited the host plant (9 of 24) than the non-host ( 3 of 24) (Fisher's exact test: $d . f .=1, P=0.047$ ). Moreover, all nine beetles stayed on the host plant, whereas only one stayed on the non-host (Fisher's exact test: $d . f .=1, P=0.005$; Figure 2). Neither the number of beetles that ended up at the edge of the arena (Fisher's exact test: $d . f .=1, P=0.073$; Figure 2) nor the ones that were found anywhere in the arena differed between the three settings (Fisher's exact test: $d . f .=1, P=0.872$; Figure 2). 


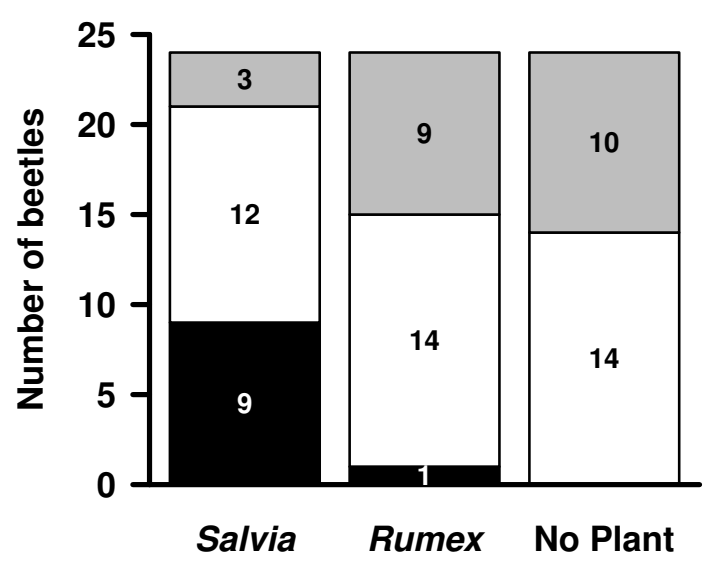

Figure 2: Distribution of $C$. canaliculata adults within a semi-natural arena at the end of the trials. A bar plot of the number of beetles found on the offered plant (black), anywhere in the arena (white), or at the edge of the arena (grey) when a host (S. pratensis), a non-host ( $R$. conglomeratus), or no plant at all was offered in the centre of the arena. Each treatment group consists of 24 beetles. Results of the statistical analyses can be found in the text.

\section{Individual-based simulations}

The individual-based simulations always predicted much smaller numbers of beetles reaching the plant than observed in the Salvia case. In the realistic scenario, in which they tended to walk along the edge after reaching it, less than $8 \%$ of the beetles reached the plant. In the setting in which the beetles were reflected at the edge of the arena, only $13 \%$ of the beetles reached the centre. Even in the most extreme scenario, in which the beetles were repelled at the edge, less than $14 \%$ of the beetles reached the centre. Thus, the probability that nine (38\%) beetles (as in the greenhouse experiment) reached the host plant in the arena by chance alone (assuming a random walking pattern) is $P_{\text {edge }}<$ 5.33 E-05 for the edge-walking scenario, $P_{\text {reflecting }}<0.002$ for the reflecting edge, and $P_{\text {repelling }}<0.003$ for the repelling edge. In contrast, three beetles could have reached the non-host by chance alone in all three scenarios $\left(P_{\text {edge }}<0.295, P_{\text {reflecting }}<0.596\right.$, $\left.P_{\text {repelling }}<0.646\right)$.

\section{Movement behaviour}

The absolute movement variables, straightness and mean walking speed, did not differ significantly between the three settings (Table 1). In contrast, the variables that describe the direction of the beetles relative to the centre of the arena, i.e. the mean distance to the centre and the mean angular deviation from walking straight to the centre of the arena, differed significantly between the three settings (mean distance: 
Table 1: Absolute movement variables of $C$. canaliculata in a semi-natural arena when a host plant (S. pratensis), a non-host plant ( $R$. conglomeratus), or no plant at all was offered in the centre of the arena. Shown are the median and the $25 \%$ and $75 \%$ quantiles (in parentheses) of the straightness, i.e. the quotient of net distance (from start to end point) and total track length, and the mean walking speed $(\mathrm{cm} / \mathrm{s}) . \mathrm{P}$ denotes the significance of the Kruskal-Wallis $H$-test. $N=24$ beetles in each setting.

\begin{tabular}{lllll}
\hline Variable & S. pratensis & R. conglomeratus & No plant & $P$ \\
\hline Straightness & $0.41(0.33-0.79)$ & $0.56(0.36-0.74)$ & $0.49(0.36-0.75)$ & 0.949 \\
Mean walking speed $(\mathrm{cm} / \mathrm{s})$ & $0.35(0.26-0.48)$ & $0.36(0.21-0.41)$ & $0.31(0.24-0.36)$ & 0.452 \\
\hline
\end{tabular}

$H=10.20, d . f .=2, P=0.006, n=24$ per setting; mean angular deviation: $H=21.24$, d.f. $=2, P<0.001, n=24$ per setting). The mean distance to the centre was significantly shorter when a host plant was offered than when either a non-host plant or no plant at all were offered (Figure 3). Likewise, the mean angular deviation from walking straight to the centre was significantly smaller in the host plant setting than in the two control settings (Figure 4).

Only when a host plant was presented was the mean distance from the centre significantly smaller than the critical value of $2 / 3 \mathrm{~m}(U=47, P=0.001, n=24)$, whereas there was no difference when the non-host or no plant was offered (Rumex: $U=143$, $P=0.855, n=24$; No Plant: $U=165, P=0.684, n=24)$. Moreover, the mean angular deviation from walking straight to the centre was only significantly smaller than

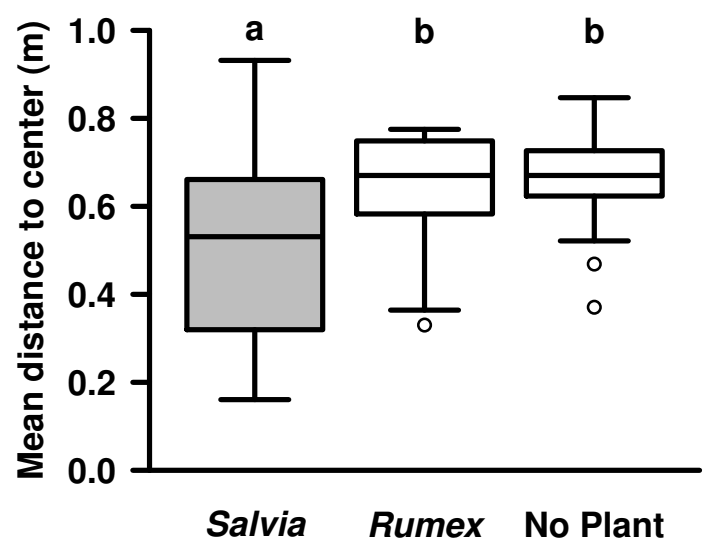

Figure 3: Relative movement of $C$. canaliculata adults within a semi-natural arena. A box-and-whisker plot of the mean distance to the centre $(\mathrm{m})$ when a host (S. pratensis), a non-host ( $R$. conglomeratus), or no plant at all was offered in the centre of the arena. The boxes represent the median, and $25 \%$ and $75 \%$ percentiles. The whiskers extend to the maximum values; circles denote outliers. Different letters denote significant differences between the groups (Salvia versus Rumex: $U=161, P=0.008$; Salvia versus No Plant: $U=149, P=0.004$; Rumex versus No Plant: $U=305, P=0.736$ ). Each treatment group consists of 24 beetles. 


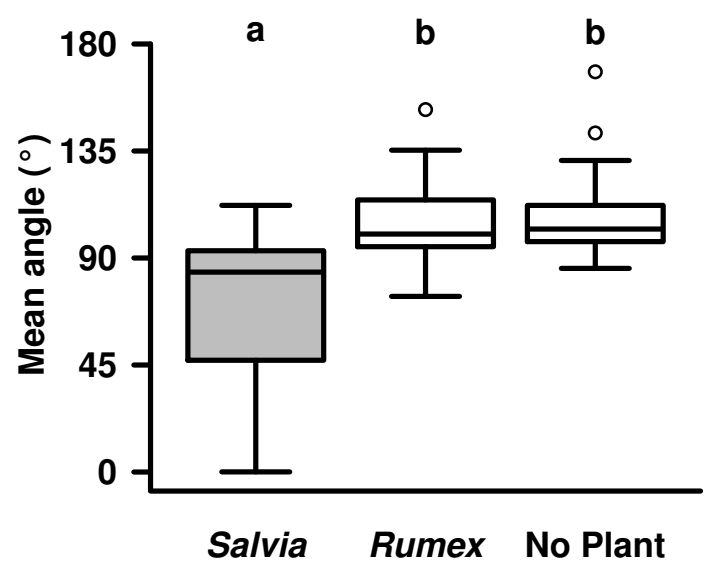

Figure 4: Relative movement of $C$. canaliculata adults within a semi-natural arena. A box-and-whisker plot of the mean angular deviation from walking straight to the centre $\left(^{\circ}\right)$ when a host $(S$. pratensis $)$, a non-host ( $R$. conglomeratus), or no plant at all was offered in the centre of the arena. The boxes represent the median, and $25 \%$ and $75 \%$ percentiles. The whiskers extend to the maximum values; circles denote outliers. Different letters denote significant differences between the groups (Salvia versus Rumex: $U=$ 107, $P<0.001$; Salvia versus No Plant: $U=85, P<0.001$; Rumex versus No Plant: $U=309, P=0.675$ ). Each treatment group consists of 24 beetles.

$90^{\circ}$ when a host plant was offered $(U=79, P=0.021, n=24)$, whereas it was significantly greater than $90^{\circ}$ when a non-host plant or no plant at all were presented in the centre (Rumex: $U=261, P<0.001, n=24$; No Plant: $U=294, P<0.001, n=24$ ).

\section{Movement behaviour depending on distance from the centre}

The standardised walking speed did not correlate significantly with the distance from the centre of the arena in any of the three settings (Salvia: $r_{s}=-0.110, P=0.067$, $n=280$; Rumex: $r_{s}=-0.079, P=0.161, n=318$; No Plant: $r_{s}=-0.040, P=0.456$, $n=351$ ). When a host plant was offered, the angular deviation from walking towards the centre of the arena showed a tendency to correlate with the distance from the centre of the arena $\left(r_{s}=-0.115, P=0.054, n=280\right)$, i.e. the deviation tended to decline with decreasing distance to the centre; however, the effect size was not very large. In the other two settings, there was no such correlation (Rumex: $r_{s}=0.006, P=0.921$, $n=318$; No Plant: $\left.r_{s}=0.096, P=0.073, n=351\right)$.

\section{DisCUSSION}

The majority of herbivorous insects have to find their host plants within a highly diverse mosaic of various non-host plant species. The host plant cues used in this process differ from species to species (Jones, 1991; Bernays \& Chapman, 1994; Bruce et al., 
2005). A recent study suggested that olfactory cues play only a minor role in host plant finding by the monophagous leaf beetle, $C$. canaliculata Laich., which is very well able to identify its host using contact cues (Heisswolf et al., 2007). This implies that the beetles are not able to locate their host plant from a distance. However, these experiments were performed under controlled laboratory conditions using a locomotion compensator, a six-chamber olfactometer, and a stem arena, which are possibly not sufficient to reveal potential differences in the beetles' behavioural response to plant stimuli. Thus, in this study, a semi-natural arena experiment was developed, in which an intact host plant was offered to the beetles, which provided visual, olfactory, and contact cues simultaneously. There, a small-scale movement pattern analysis was used to re-examine the process of host plant finding in $C$. canaliculata.

Looking first at the distribution of beetles during and at the end of the trials, significantly more beetles were found on the host plant than when a non-host plant was presented, and no beetles left the host plant once they had reached it, whereas two of three did leave the non-host plant. This confirms our previous laboratory results, which showed that $C$. canaliculata is able to recognise its host, $S$. pratensis, using contact cues (Heisswolf et al., 2007). Still, it is no sufficient proof for host plant recognition from a distance. However, individual-based simulation studies showed that three (or more) hits in 24 random searching animals is well inside the range of a binomial distribution for all implemented behavioural patterns at the edge of the arena, whereas nine (or more) hits in 24 trials never reached a probability of more than 0.003 (even with a repelling edge) and was an order of magnitude smaller in the realistic scenario in which the beetles tended to walk along the edge of the arena. Thus, a detailed analysis of the absolute and relative movement variables of $C$. canaliculata may shed more light on the host finding process in this species.

Regarding the absolute movement variables, straightness and mean walking speed, no significant differences could be detected when the host (S. pratensis), the non-host (R. conglomeratus), or no plant were placed in the centre of the arena. Possible explanations are that these absolute variables may be rather fixed in this species - as suggested by McIntyre \& Vaughn (1997) for two Eleodes species - or determined by the surface on which the beetles walked, which was the same in all settings. Likewise, the walking speed did not change systematically with the distance from the centre. Regarding this observation, there is also no clear-cut null hypothesis to be found in the literature on the expected relationship between walking speed and the distance to a potential stimulus (visual or olfactory). For olfactory cues, both the hypothesis that insects increase their walking speed when approaching an attractive odour source and the hypothesis that they will walk more slowly in order to be able to locate the source are quite common (e.g. Thiery \& Visser, 1986; Bolter et al., 1997; McMahon 
\& Guerin, 2002). Thus, it remains unclear whether the observed lack of correlation between the walking speed and the presence as well as the distance to the host plant is of any importance in the process of host plant finding.

Although the beetles showed no differences in the absolute movement variables, the relative variables, i.e. mean distance to the centre and mean angular deviation from walking straight to the centre, differed significantly between the three settings: the beetles walked closer to the centre and oriented more towards the centre of the arena when a host plant was presented there. Likewise, the angular deviation from walking straight to the centre tended to decrease with decreasing distance from the centre. Although the effect size of these variables was not very large, these results clearly indicate that $C$. canaliculata is able to recognise its host plant from a distance. To control for a potential bias in the data that may stem from the fact that beetles who found the host plant did not leave it again and thus contributed to the data only with a movement towards the plant, further analyses were conducted in which these beetles were completely removed from the analysis. However, in this case also the differences in the relative movement patterns were still significant between the 'Salvia' group and the two control groups (data not shown).

Owing to the very similar growth form of S. pratensis and R. conglomeratus (Figure 1), it could be hypothesized that the beetles use olfactory cues for host plant identification. However, this similarity in shape may only appear to the human eye and not to the beetles, as they may even be able to use the spectral composition of the plant tissue for host plant recognition (Bullas-Appleton et al., 2004; Fischer et al., 2004; Mäntylä et al., 2004). Furthermore, the beetles may use a combination of olfactory and visual cues, which has also been found in other herbivorous insects (McIntyre \& Vaughn, 1997; Cook \& Neal, 1999; Strom et al., 1999; Barata \& Araújo, 2001; Szentesi et al., 2002). As in this study only one host plant and one non-host plant individual were used, these questions cannot be finally answered, but further studies with several different plant individuals are needed to corroborate our results and to disentangle the olfactory and visual components of host plant recognition in C. canaliculata. Furthermore, only one non-host species was used for experimentation, so the experiments should be repeated with several other non-host species. An even simpler approach would be to use plant dummies on to which extracts of host and non-host plants are applied.

In summary, this study shows that $C$. canaliculata is able to recognise its host plant, $S$. pratensis, from a distance, although a previous laboratory study gave no such indication (Heisswolf et al., 2007). Thus, the analysis of movement patterns in a seminatural arena seems to be a useful way of discovering behavioural responses to host plant cues that could not be detected with standard laboratory methods. 


\section{ACKNOWLEDGEMENTS}

We thank Thomas Hovestadt for statistical advice, Brenda Pfenning for providing the basics of the experimental design, and Roland Bickel for building the arena. We are grateful to two anonymous referees for their helpful comments on an earlier version of the manuscript. A.H. was financially supported through a scholarship granted by the Evangelisches Studienwerk e.V. Villigst.

\section{REFERENCES}

Baker, T. C. \& Vickers, N. J. (1997). Pheromone-mediated flight in moths. In: Cardé, R. T. \& Minks, A. K. (eds.) Pheromone Research: New Directions, Chapman and Hall, New York, pp. 248-264. 2

Barata, E. N. \& Araújo, J. (2001). Olfactory orientation responses of the eucalyptus woodborer, Phoracantha semipunctata, to host plant in a wind tunnel. Physiological Entomology 26: 26-37. 2, 11

Barata, E. N., Pickett, J. A., Wadhams, L. J., Woodcock, C. M. \& Mustaparta, H. (2000). Identification of host and nonhost semiochemicals of eucalyptus woodborer Phoracantha semipunctata by gas chromatographyelectroantennography. Journal of Chemical Ecology 26: 1877-1895. 1

Bartlet, E., Blight, M. M., Lane, P. \& Williams, I. H. (1997). The responses of the cabbage seed weevil Ceutorhynchus assimilis to volatile compounds from oilseed rape in a linear track olfactometer. Entomologia Experimentalis et Applicata 85: 257-262. 1

Bernays, E. A. \& Chapman, R. F. (1994). Host-Plant Selection by Phytophagous Insects. Chapman and Hall, New York. 9

Bivand, R., Leisch, F. \& Mächler, M. (2004). Pixmap: Bitmap Images ('Pixel Maps'). R package, Version 0.4-2, URL http://www.r-project.org. 4

Blight, M. M., Pickett, J. A., Wadhams, L. J. \& Woodcock, C. M. (1995). Antennal perception of oilseed rape, Brassica napus (Brassicaceae), volatiles by the cabbage seed weevil Ceutorhynchus assimilis (Coleoptera, Curculionidae). Journal of Chemical Ecology 21: 1649-1664. 1

Böhm, H. (1995). Dynamic properties of orientation to turbulent air current by walking carrion beetles. Journal of Experimental Biology 198: 1995-2005. 2

Bolter, C. J., Dicke, M., van, J. J. A. L., Visser, J. H. \& Posthumus, M. A. (1997). Attraction of Colorado potato beetle to herbivore-damaged plants during herbivory and after its termination. Journal of Chemical Ecology 23: 1003-1023. 10

Bourgeois, J. \& Scherdlin, P. (1899). Catalogue des Coléoptères des Vosges et des regions limitrophes. Decker, Colmar. 3

Bruce, T. J. A., Wadhams, L. J. \& Woodcock, C. M. (2005). Insect host location: a volatile situation. Trends in Plant Science 10: 269-274. 1,9

Bullas-Appleton, E. S., Otis, G., Gillard, C. \& Schaafsma, A. W. (2004). Potato leafhopper (Homoptera: Cicadellidae) varietal preferences in edible beans in relation to visual and olfactory cues. Environmental Entomology 33: 13811388. 11

Byers, J. A. (2001). Correlated random walk equations of animal dispersal resolved by simulation. Ecology 82: 16801690. 5 
Cook, C. A. \& Neal, J. J. (1999). Plant finding and acceptance behaviors of Anasa tristis (DeGeer). Journal of Insect Behavior 12: 781-799. 11

Düll, R. \& Kutzelnigg, H. (2005). Taschenlexikon der Pflanzen Deutschlands. Quelle \& Meyer, Wiebelsheim. 3

Feeny, P., Paauwe, K. L. \& Demong, N. J. (1970). Flea beetles and mustard oils: Host plant specificity of Phyllotreta cruciferae and P. striolata adults (Coleoptera: Chrysomelidae). Annals of the Entomological Society of America 63: $832-841.1$

Fischer, S., Samietz, J., Wäckers, F. L. \& Dorn, S. (2004). Perception of chromatic cues during host location by the pupal parasitoid Pimpla turionellae (L.) (Hymenoptera: Ichneumonidae). Environmental Entomology 33: 81-87. 11

Graser, K. (1984). Thüringer Funde von Cassida (U. G. Lordiconia RTTR) canaliculata LAICH. 1781 (Col., Chrysomelidae). Entomologische Nachrichten und Berichte 28: 86-87. 3

Grünbaum, D. (1998). Using spatially explicit models to characterize foraging performance in heterogeneous landscapes. American Naturalist 151: 97-115. 5

Guerrieri, E. (1996). Flight behaviour of Encarsia formosa in response to plant and host stimuli. Entomologia Experimentalis et Applicata 82: 129-133. 2

Heisswolf, A., Gabler, D., Obermaier, E. \& Müller, C. (2007). Olfactory versus contact cues in host plant recognition of a monophagous Chrysomelid beetle. Journal of Insect Behavior 20: 247-266. 2, 10, 11

Heisswolf, A., Obermaier, E. \& Poethke, H. J. (2005). Selection of large host plants for oviposition by a monophagous leaf beetle: nutritional quality or enemy-free space? Ecological Entomology 30: 299-306. 3

Heisswolf, A., Poethke, H. J. \& Obermaier, E. (2006). Multitrophic influences on egg distribution in a specialized leaf beetle at multiple spatial scales. Basic and Applied Ecology 7: 565-576. 3

Jermy, T., Szentesi, A. \& Horváth, J. (1988). Host plant finding in phytophagous insects: the case of the Colorado potato beetle. Entomologia Experimentalis et Applicata 49: 83-98. 2

Jones, R. E. (1991). Host location and oviposition on plants. In: Bailey, W. J. \& Ridsdill, J. (eds.) Reproductive Behaviour of Insects. Individuals and Populations, Chapman \& Hall, London, pp. 108-138. 9

Kalberer, N. M., Turlings, T. C. J. \& Rahier, M. (2001). Attraction of a leaf beetle (Oreina cacaliae) to damaged host plants. Journal of Chemical Ecology 27: 647-661. 1

Kalberer, N. M., Turlings, T. C. J. \& Rahier, M. (2005). An alternative hibernation strategy involving sunexposed "hotspots", dispersal by flight, and host plant finding by olfaction in an alpine leaf beetle. Entomologia Experimentalis et Applicata 114: 189-196. 1, 2

Kareiva, P. \& Shigesada, N. (1983). Analysing insect movements as a correlated random walk. Oecologia 56: 234-238. 5

Kitching, R. (1971). A simple simulation model of dispersal of animals among units of discrete habitats. Oecologia 7: 95-116. 5

Mäntylä, E., Klemola, T. \& Haukioja, E. (2004). Attraction of willow warblers to sawfly-damaged mountain birches: novel function of inducible plant defences? Ecology Letters 7: 915-918. 11

McIntyre, N. E. \& Vaughn, T. T. (1997). Effects of food deprivation and olfactory and visual cues on movement patterns of two Eleodes species (Coleoptera: Tenebrionidae) in a wind tunnel. Annals of the Entomological Society of America 90: 260-265. 2, 10, 11

McMahon, C. \& Guerin, P. M. (2002). Attraction of the tropical bont tick, Amblyomma variegatum, to human breath and to the breath components acetone, $\mathrm{NO}$ and $\mathrm{CO}_{2}$. Naturwissenschaften 89: 311-315. 10 
Pfenning, B., Hovestadt, T. \& Poethke, H. J. (2004). The effect of patch constellation on the exchange of individuals between habitat-islands. Ecological Modelling 180: 515-522. 5

R Development Core Team (2005). R: A language and environment for statistical computing. R Foundation for Statistical Computing, Vienna, Austria, URL http: //www.r-project.org. 4, 6

Reitter, E. (1912). Fauna Germanica, Käfer. Lutz, Stuttgart. 3

Schmeil, O. \& Fitschen, J. (1996). Flora von Deutschland und angrenzender Länder. Quelle \& Meyer, Wiesbaden. 3

Schmitz, O. J. (2000). Combining field experiments and individual-based modeling to identify the dynamically relevant organizational scale in a field system. Oikos 89: 471-484. 5

Steinhausen, W. (1949). Morphologie, Biologie und Ökologie der Entwicklungsstadien der in Niedersachsen heimischen Schildkäfer (Cassidinae Chrysomelidae Coleoptera) und deren Bedeutung für die Landwirtschaft. Ph.D. thesis, Technische Hochschule Braunschweig. 3

Strom, B. L., Roton, L. M., Goyer, R. A. \& Meeker, J. R. (1999). Visual and semiochemical disruption of host finding in the southern pine beetle. Ecological Applications 9: 1028-1038. 11

Szentesi, A., Weber, D. C. \& Jermy, T. (2002). Role of visual stimuli in host and mate location of the Colorado potato beetle. Entomologia Experimentalis et Applicata 105: 141-152. 11

Thiery, D. \& Visser, J. H. (1986). Masking of host plant odour in the olfactory orientation of the Colorado potato beetle. Entomologia Experimentalis et Applicata 41: 165-172. 10

Tinzaara, W., Dicke, M., van Huis, A., van Loon, J. J. A. \& Gold, C. S. (2003). Different bioassays for investigating orientation responses of the banana weevil, Cosmopolites sordidus, show additive effects of host plant volatiles and a synthetic male-produced aggregation pheromone. Entomologia Experimentalis et Applicata 106: 169-175. 2

Trautner, J., Geigenmüller, K. \& Bense, U. (1989). Käfer beobachten, bestimmen. Neumann-Neudamm, Melsungen. 3

Turchin, P. (1998). Quantitative Analysis of Movement: Measuring and Modeling Population Redistribution in Animals and Plants. Sinauer, Sunderland. 5

van Loon, J. J. A., de Vos, E. W. \& Dicke, M. (2000). Orientation behaviour of the predatory hemipteran Perillus bioculatus to plant and prey odours. Entomologia Experimentalis et Applicata 96: 51-58. 2

van Tol, R. W. H. M. \& Visser, J. H. (2002). Olfactory antennal responses of the vine weevil Otiorhynchus sulcatus to plant volatiles. Entomologia Experimentalis et Applicata 102: 49-64. 1

Vickers, N. J. (2000). Mechanisms of animal navigation in odor plumes. Biological Bulletin 198: 203-212. 2

Visser, J. H. \& Avé, D. A. (1978). General green leaf volatiles in the olfactory orientation of the Colorado beetle, Leptinotarsa decemlineata. Entomologia Experimentalis et Applicata 24: 738-749. 1

Wencker, J. \& Silbermann, G. (1866). Catalogue des Coléoptères de l'Alsace et des Vosgues. Silbermann, Strasbourg. 3

Willis, M. A., David, C. T., Murlis, J. \& Cardé, R. T. (1994). Effects of pheromone plume structure and visual stimuli on the pheromone-modulated upwind flight of male gypsy moths (Lymantria dispar) in a forest (Lepidoptera: Lymantriidae). Journal of Insect Behavior 7: 385-409. 2

Witzgall, P. (1997). Modulation of pheromone-mediated flight in male moths. In: Cardé, R. \& Minks, A. K. (eds.) Pheromone Research: New Directions, Chapman and Hall, New York, pp. 265-274. 2

Zhang, Q. H. \& Schlyter, F. (2004). Olfactory recognition and behavioural avoidance of angiosperm nonhost volatiles by conifer-inhabiting bark beetles. Agricultural and Forest Entomology 6: 1-19. 1 